\title{
Architectural B-cell organization in skeletal muscle identifies subtypes of dermatomyositis
}

Josefine Radke, MD, Randi Koll, Corinna Preuße, PhD, Debora Pehl, MD, Kremena Todorova, MD, Constanze Schönemann, MD, Yves Allenbach, MD, PhD, Eleonora Aronica, MD, Marianne de Visser, MD, Frank L. Heppner, MD, Joachim Weis, MD, Soroush Doostkam, MD, Thierry Maisonobe, MD,

Olivier Benveniste, MD, PhD, Hans-Hilmar Goebel, MD, and Werner Stenzel, MD

Neurol Neuroimmunol Neuroinflamm 2018;5:e451. doi:10.1212/NXI.0000000000000451

\section{Abstract \\ Objective}

To study the B-cell content, organization, and existence of distinct B-cell subpopulations in relation to the expression of type 1 interferon signature related genes in dermatomyositis (DM).

\section{Methods}

Evaluation of skeletal muscle biopsies from patients with adult DM (aDM) and juvenile DM (jDM) by histology, immunohistochemistry, electron microscopy, and quantitative reversetranscription PCR.

\section{Results}

We defined 3 aDM subgroups-classic (containing occasional B cells without clusters), Bcell-rich, and follicle-like aDM-further elucidating IM B-lymphocyte maturation and immunity. The quantity of B cells and formation of ectopic lymphoid structures in a subset of patients with aDM were associated with a specific profile of cytokines and chemokines involved in lymphoid neogenesis. Levels of type 1 interferon signature related gene expression paralleled B-cell content and architectural organization and link B-cell immunity to the interferon type I signature.

\section{Conclusion}

These data corroborate the important role of B cells in DM, highlighting the direct link between humoral mechanisms as key players in B-cell immunity and the role of type I interferon-related immunity.

\author{
Correspondence \\ Dr. Radke \\ josefine.radke@charite.de
}




\section{Glossary}

$\mathbf{a D M}=$ adult dermatomyositis; $\mathbf{C K}=$ creatine kinase $\mathbf{D M}=$ dermatomyositis; $\mathbf{E L S}=$ ectopic lymphoid structure; $\mathbf{E M}=$ electron microscopy; ENMC = European Neuromuscular Centre; HEV = high endothelial venule; IFN = interferon; jDM = juvenile dermatomyositis; $\mathbf{M H C}$ = major histocompatibility complex; $\mathbf{m R N A}=$ messenger RNA; $\mathbf{M x A}$ = myxovirus resistance gene A; $\mathbf{q P C R}=$ quantitative PCR; RIN = RNA integrity number; TRI = tubuloreticular inclusion; VAS = visual analog scale.

Dermatomyositis (DM) is an idiopathic inflammatory disease of the skeletal muscle and skin, clinically characterized by symmetrical proximal muscle weakness and typical skin lesions. A clear distinction is made between juvenile $\mathrm{DM}(\mathrm{jDM})$ and adult $\mathrm{DM}(\mathrm{aDM})$ by (1) agejDM onset is below the age of 16 years-and (2) distinct clinical presentation with, e.g., calcinosis cutis in jDM, rarely discovered in $\mathrm{aDM}^{1}{ }^{1}(3)$ possible association with cancer in $\mathrm{aDM}$, which is absent in jDM, and (4) the occurrence of bowel vasculitis in $\mathrm{jDM}$, which is rare in $\mathrm{aDM}$. Furthermore, the involvement of molecular pathways of hypoxia and innate immunity has been found to be regulated differently in aDM and jDM. ${ }^{2}$ Beside genetic predispositions, ${ }^{3}$ the role of type I interferons (IFNs) has been identified as being prominently involved in $\mathrm{DM}^{2,4}$ The treatment mainly relies on immunosuppressive and immunomodulatory agents, including CD20-targeting (Bcell depletion) strategies. ${ }^{5}$ Still, there are a significant number of nonresponders to immunosuppressive therapy (in aDM about 30\%) limiting successful treatment options. $^{6}$

Histomorphologically, perifascicular atrophy and specific injury to capillaries and perifascicular myofibers are pathognomonic in DM. The inflammatory infiltrate consists of dendritic cells, macrophages, $\mathrm{CD} 4^{+}$and $\mathrm{CD} 8^{+} \mathrm{T}$ cells, natural killer cells, plasmacytoid dendritic cells, and B cells, the significance of which is of utmost interest as potential and specific therapeutic targets. ${ }^{7,8}$ Nevertheless, the composition and regional distribution of the inflammatory cell infiltrates in skeletal muscle tissue vary conspicuously among patients with DM, ranging from sparse mixed infiltrates to nodular collections of highly organized B- and T-cell compartmentalization. These nodular collections may provide a permissive environment for clonal expansion and maturation of B cells in myositis muscle. ${ }^{8}$ We previously reported on the formation of ectopic lymphoid structures (ELSs) within the muscle tissue of patients with aDM. ${ }^{9}$ ELS formation has been described in other autoimmune diseases, e.g., MS, rheumatoid arthritis, and Sjögren syndrome, ${ }^{10,11}$ but seems to be very rare in adult and jDM. ${ }^{9,12}$ Nevertheless, the molecular mechanisms leading to formation of ELSs with germinal center-like reactions have not been fully elucidated. ${ }^{13}$ Therefore, we aim to further characterize the cytokine and chemokine milieu as well as the microarchitecture of aDMassociated B-cell infiltrates and ELSs. Based on these results, we discuss their functional and immunopathogenic implications.

\section{Methods}

\section{Patient cohort}

The available clinical and demographic information of all 23 patients enrolled in this study is listed in table e-1 (links.lww. $\mathrm{com} / \mathrm{NXI} / \mathrm{A} 40)$. We included patients with typical symptoms of DM including characteristic livedoid skin rash/Gottron papules, proximal tetraparesis, muscle pain, and elevated creatine kinase (CK) levels. Furthermore, the ultrastructural presence of tubuloreticular inclusions (TRIs) in endothelial cells, the presence/ absence of autoantibodies, including anti-Jo1, -Mi2, -SRP, -PL7, -PL12, anti-Ro52, or -KU, serum CK, and the clinical outcomes were documented. Anti-Mi2 autoantibody-positive patients were included in the DM group, whereas patients with antisynthetase autoantibodies or necrotizing myopathy and antiSRP autoantibodies were excluded. Patients with aDM were selected based on the presence or absence of B-cell infiltrates and ELSs. Patients with jDM had classic DM morphology without significant numbers of B cells or ELSs.

\section{Standard protocol approvals, registrations, and patient consents}

Informed consent was obtained from all patients at each institution involved. Ethical approval (EA1/204/11) was granted by the Charité Ethics Committee.

\section{Skeletal muscle specimens}

We analyzed skeletal muscle biopsies from patients diagnosed with $\mathrm{aDM}(\mathrm{n}=16)$, according to the clinico-morphological European Neuromuscular Centre (ENMC) criteria, ${ }^{14}$ and jDM $(\mathrm{n}=4)$, according to the ENMC and international consensus criteria for the severity of jDM disease. ${ }^{15}$ In addition, we investigated control skeletal muscle biopsies $(\mathrm{n}=3)$ from patients with nonspecific complaints in a context of "fatigue-like" symptoms, but without clinical muscle weakness, absence of morphologic abnormalities on skeletal muscle biopsy, or elevated CK levels, or laboratory evidence of any systemic inflammation. We have previously shown that there were no differences in gene expression levels of adult and juvenile controls. ${ }^{2}$ The muscle specimens were cryopreserved at $-80^{\circ} \mathrm{C}$ for routine diagnostic workup or preserved in glutaraldehyde for ultrastructural analysis. All DM samples were evaluated according to an adapted visual analog scale (VAS), which was originally introduced for $\mathrm{jDM}^{15}$ In analogy to the original VAS, we assessed the muscle involvement of all 4 compartments/ domains (inflammatory, vascular, muscular, and connective tissue) separately. Special stains used to evaluate each domain included the following: CD3, CD45, CD68 (inflammatory), CD31 (vascular), major histocompatibility complex (MHC) 
class I (muscular), and Elastica van Gieson (connective tissue). The global impression of each domain was scored on a 0-10point scale to illustrate the association of DM subgroups and domain-specific muscle involvement. VAS scoring was performed by J.R. and W.S. in a blinded fashion for all samples. DM samples were further analyzed based on the presence of specialized B-cell subpopulations and B- and T-cell compartmentalization (organized separation of specialized $\mathrm{T}$ and $\mathrm{B}$ cells). Three histologic $\mathrm{aDM}$ subgroups were defined: classic $\mathrm{aDM}(\mathrm{n}=$ 6), B-cell-rich $\mathrm{aDM}(\mathrm{n}=7)$, and follicle-like $\mathrm{aDM}(\mathrm{n}=3)$, the latter required the presence of ectopic germinal center formation.

\section{Histologic, enzyme histochemical, immunohistochemical, and immunofluorescence procedures}

Routine stains were performed on $7-\mu \mathrm{m}$ cryostat sections according to standard procedures. Immunohistochemical, double immunofluorescence stains and electron microscopy (EM) were performed as described previously. ${ }^{2,16}$ Primary antibodies are listed in table e-2 (links.lww.com/NXI/A40).

\section{RNA extraction}

Total RNA was extracted from muscle specimens using the mirVana miRNA Isolation Kit (Life Technologies, Darmstadt, Germany) according to the manufacturer's instructions. The RNA integrity number (RIN) was determined using an Agilent 2100 Bioanalyser (Agilent Technologies, Santa Clara, CA). The RNA 6000 Nano LabChip Kit (Agilent Technologies) was used to analyze the degradation level. All 23 samples fulfilled the RNA quality criteria (RIN > 8).

\section{Quantitative reverse-transcription PCR}

Complementary DNA was synthesized using an $\mathrm{RT}^{2}$ First Strand Kit (Qiagen, Hilden, Germany). Real-time PCR was performed using a custom $\mathrm{RT}^{2}$ profiler quantitative $\mathrm{PCR}$ (qPCR) assay (Qiagen). Glyceraldehyde 3-phosphate dehydrogenase was included in the custom-made qPCR assay as an internal control to normalize the expression of the target genes. The qPCR assay identification numbers are listed in table e-3 (links.lww.com/NXI/A40). A summary table of the qPCR results can be found in the supplementary material (table e-4).

\section{Statistical analysis}

Kruskal-Wallis one-way analysis of variance followed by Bonferroni-Dunn correction of the post hoc tests was used to analyze quantitative differences of messenger RNA (mRNA) transcripts and the VAS score. Data are presented as mean \pm SEM. The level of significance was set at $p<0.05$. GraphPad Prism 5.02 software (GraphPad Software, Inc., La Jolla, CA) was used for statistical analysis.

\section{Results}

\section{Morphological analysis}

We performed histopathologic evaluation of serial sections of muscle samples (figure 1) based on 4 different domains (inflammatory, vascular, muscle fiber, and connective tissue; figure 2). DM samples were further classified based on the location, organization, and architecture of the inflammatory infiltrate.

\section{Inflammatory domain}

To further characterize the inflammatory infiltrate in all DM subgroups, we performed various immunohistochemical stains. In skeletal muscle biopsies of patients with jDM and classic $\mathrm{aDM}$, the inflammatory infiltrate was diffusely distributed and mainly located in the perimysium and partly in the adjacent endomysium (figure 1, A, B, G, and H). It consisted of $\mathrm{CD}^{+} 5^{+}$ lymphocytes (data not shown), $\mathrm{CD}^{+} 8^{+}$macrophages (figure 2, $\mathrm{A}$ and D), $\mathrm{CD}^{+} \mathrm{T}$-lymphocytes (data not shown), and only few $\mathrm{CD}^{2} 0^{+}$B-lymphocytes (figures 3, A and D). By contrast, samples of B-cell-rich and follicle-like aDM muscle biopsies demonstrated significantly more inflammatory infiltrates, which were located in both the perimysium and endomysium (figure 1, $\mathrm{C}-\mathrm{F}$ ), consisting of many $\mathrm{CD} 20^{+}$B-lymphocytes (figure 3, B and $\mathrm{C}$ ). B-cell-rich aDM samples showed dense $\mathrm{CD} 20^{+} \mathrm{B}$-cell aggregates, lacking T-B compartmentalization (figures $1, \mathrm{C}$ and $\mathrm{D}, 3 \mathrm{~B}$ ). Muscle specimens of follicle-like aDM demonstrated follicle-like structures, resembling tertiary lymphoid organs with germinal centers and dark and light zone organization (figure 1, $\mathrm{E}$ and $\mathrm{F}$ ).

\section{Vascular domain}

Previous studies have suggested that the mean ratio of capillaries to muscle fibers in healthy muscle tissue is usually 1.0. ${ }^{17}$ We performed immunohistochemical stains for CD31 to evaluate the capillary density/the capillary-to-fiber ratio in all muscle samples (figure 2, I-L). Capillary loss was most prominent in jDM (figure 2, L and $\mathrm{Q}$ ) and milder in Bcell-rich (figure 2, J and Q), follicle-like (figure 2, K and Q), and classic aDM (figure 2, I and Q), in the latter, like in jDM, predominantly affecting the perifascicular region (figure 2, I and $\mathrm{L}$; inserts). Demarcated infarction of small groups of fibers in muscle fascicles with focal loss of normal cytoarchitecture was present exclusively in $2 \mathrm{jDM}$ muscle specimens (figure $1 \mathrm{H}$, scattered line).

\section{Muscle fiber domain}

All muscle biopsies revealed upregulation of MHC class I (figure 2) and partially of MHC class II (data not shown) molecules on the muscle fiber surface. In jDM and classic aDM, expression of MHC class I molecules was seen predominant in the perifascicular region ( 2 patients: figure $2, \mathrm{Ea}, \mathrm{Eb}$, and $\mathrm{H}$ [arrowheads]), in B-cell-rich and follicle-like aDM on the sarcolemma of all muscle fibers with perifascicular enhancement (figure 2, F and $\mathrm{G}$ ). Of interest, perifascicular atrophy was most prominent in $\mathrm{jDM}$ (figure 1, G and $\mathrm{H}$ ) and classic aDM (figure 1, A and B) and less pronounced in B-cell-rich (figure 1, C and D) and follicle-like aDM (figure $1, \mathrm{E}$ and $\mathrm{F}$ ).

\section{Connective tissue domain}

Increased perimysial and endomysial connective tissue was seen in all muscle samples (figure 2, M-P), but was generally 

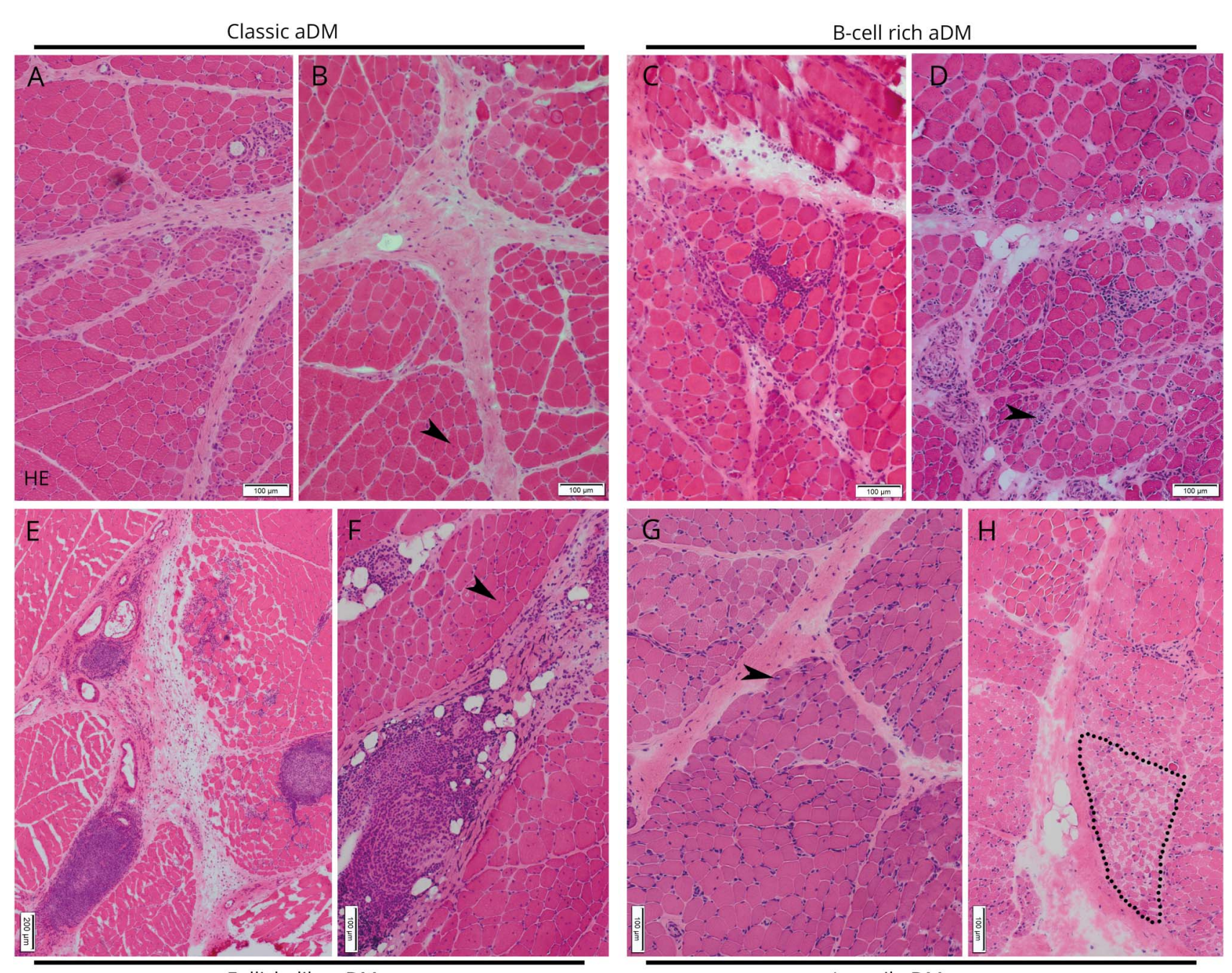

Follicle-like aDM

Juvenile DM

Classic aDM (A, B) with characteristic perifascicular atrophy. B-cell-rich (C, D) and follicle-like aDM (E, F) with dense lymphocytic aggregates and jDM (G, H) with demarcated infarction of small muscle fascicles with focal loss of normal microarchitecture (scattered line). Internalized myonuclei (B, $F$, arrowheads), myophagocytosis ( $D$, arrowhead), and the presence of nonrimmed vacuoles ( $G$, arrowhead) were seen in all muscle specimens but were more often detected in B-cell-rich and follicle-like aDM and in jDM. aDM = adult dermatomyositis; jDM = juvenile dermatomyositis.

more pronounced in samples with extensive inflammatory infiltration (B-cell-rich and follicle-like aDM; figure 2, N, O, and $\mathrm{Q}$ ). However, perimysial fragmentation of connective tissue or alkaline phosphatase activity was absent in all specimens.

\section{Role of type 1 IFN cytokines in different aDM subtypes}

We studied a comprehensive panel of genes encoding cytokine and adhesion factors, associated with, e.g., innate and adaptive immunity, inflammatory response, apoptosis, B-cell homeostasis, and germinal center formation of which many play an essential part in regulating type I IFN-induced activation and interferon-stimulated gene (ISG) transcription and translation. We detected very high expression levels of STAT3 (figure e-1A, links.lww.com/NXI/A40) and IFNstimulated exonuclease gene $20 \mathrm{kDa}$ (ISG20) in all $\mathrm{DM}$ subgroups (figure e-1B). ISG20 staining was in fact strong on the sarcoplasm of perifascicular fibers in jDM and classic $\mathrm{aDM}$ (figure 4D, arrowheads) and more diffuse in B-cell-rich and follicle-like aDM. Overexpression of myxovirus resistance gene $\mathrm{A}(\mathrm{MxA})$-marker for ISG induction and IFN response $^{18,19}$ - was detected in the perifascicular region of all cases, but was - in contrast to ISG20 (figure 4D, arrows) additionally strongly expressed by $\mathrm{B}$ cells in B-cell-rich and follicle-like aDM (figure 4C, arrowheads). MxA staining was also found on capillary walls (figure 4C, arrows) linking this molecule to development of TRIs in endothelial cells and interestingly in B cells (figure 4B, arrowheads), which are held to be a consequence of increased IFN expression. ${ }^{16,20} \mathrm{We}$ further detected that many of the type 1 IFN-inducible genes-identified using INTERFEROME v2.01 21 -were highly upregulated in muscle samples with high B-cell content (B-cell-rich and follicle-like aDM). In fact, CCL19 (figure 


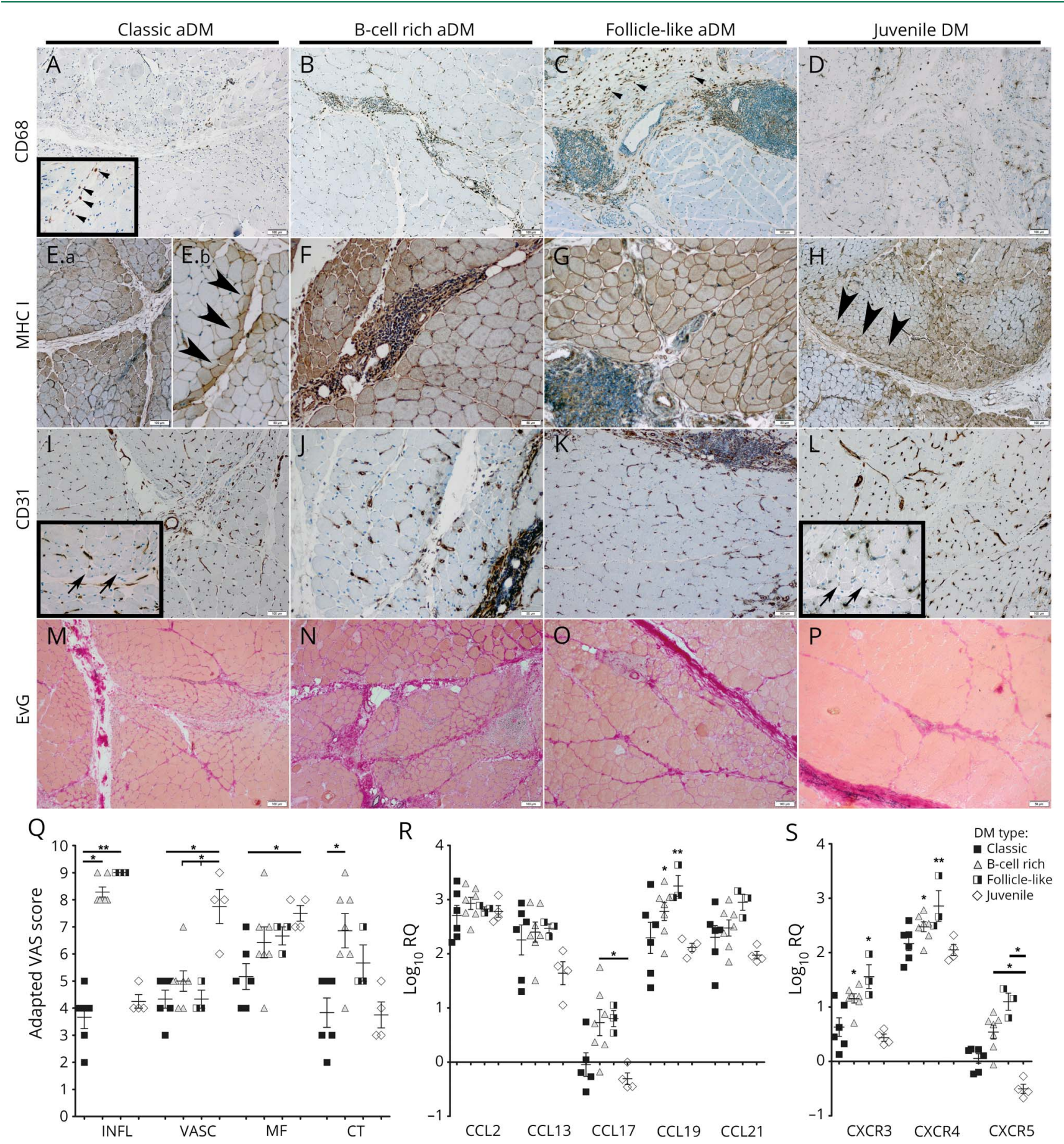

Muscle specimens were evaluated based on 4 domains (inflammatory [INFL], vascular [VASC], muscle fiber [MF], and connective tissue [CT]). In jDM and classic aDM, $\mathrm{CD}^{+} 8^{+}$macrophages were diffusely distributed in the perimysium and adjacent endomysium (A, arrowheads; D). In B-cell-rich and follicle-like $\mathrm{aDM}, \mathrm{CD}^{+} 8^{+}$macrophages were predominantly seen in the periphery of the lymphocytic aggregates (B, C, arrowheads). Expression of MHC class I molecules was predominantly seen in the perifascicular region of jDM and classic aDM muscle samples (2 patients: Ea and Eb, arrowheads; $\mathrm{H}$, arrowheads) and in Bcell-rich and follicle-like aDM on the sarcolemma of all muscle fibers with perifascicular enhancement $(F, G)$. CD31 highlighted the capillary loss, which was most prominent in the perifascicular region in jDM (L, arrows) and milder in classic (I, arrows), B-cell-rich, and follicle-like aDM (, K). Elastica van Gieson (EvG) staining was used to evaluate IM fibrosis (M-P), which was more prominent in B-cell-rich (N) and follicle-like aDM (O) than in jDM (P) and classic aDM (M). (Q) Results of the evaluation of the adapted VAS score (higher scores = more disease activity). (R, S) mRNA expression of chemokines CCL2,-13,-17,-19,-21 and chemokine receptors CXCR3,-4,-5 in different DM subgroups was measured by real-time PCR (RT-PCR). The $\triangle C T$ of healthy controls was subtracted from the $\Delta C T$ of patients with DM to determine the differences $(\Delta \Delta C T)$ and fold change $\left(2^{\wedge}-\Delta \Delta C T\right)$ of gene expression. Gene expression was illustrated by the log 10 of fold change values compared with the normal controls. Results show mean $\pm \mathrm{SEM}$. ${ }^{*} p<0.05,{ }^{*} p<0.01$. aDM $=$ adult dermatomyositis; DM $=$ dermatomyositis; $\mathrm{IM}=$ intramuscular; jDM = juvenile dermatomyositis; mRNA = messenger RNA. 
Figure 3 Morphologic and molecular analyses of B-cell infiltration and ELS formation in DM

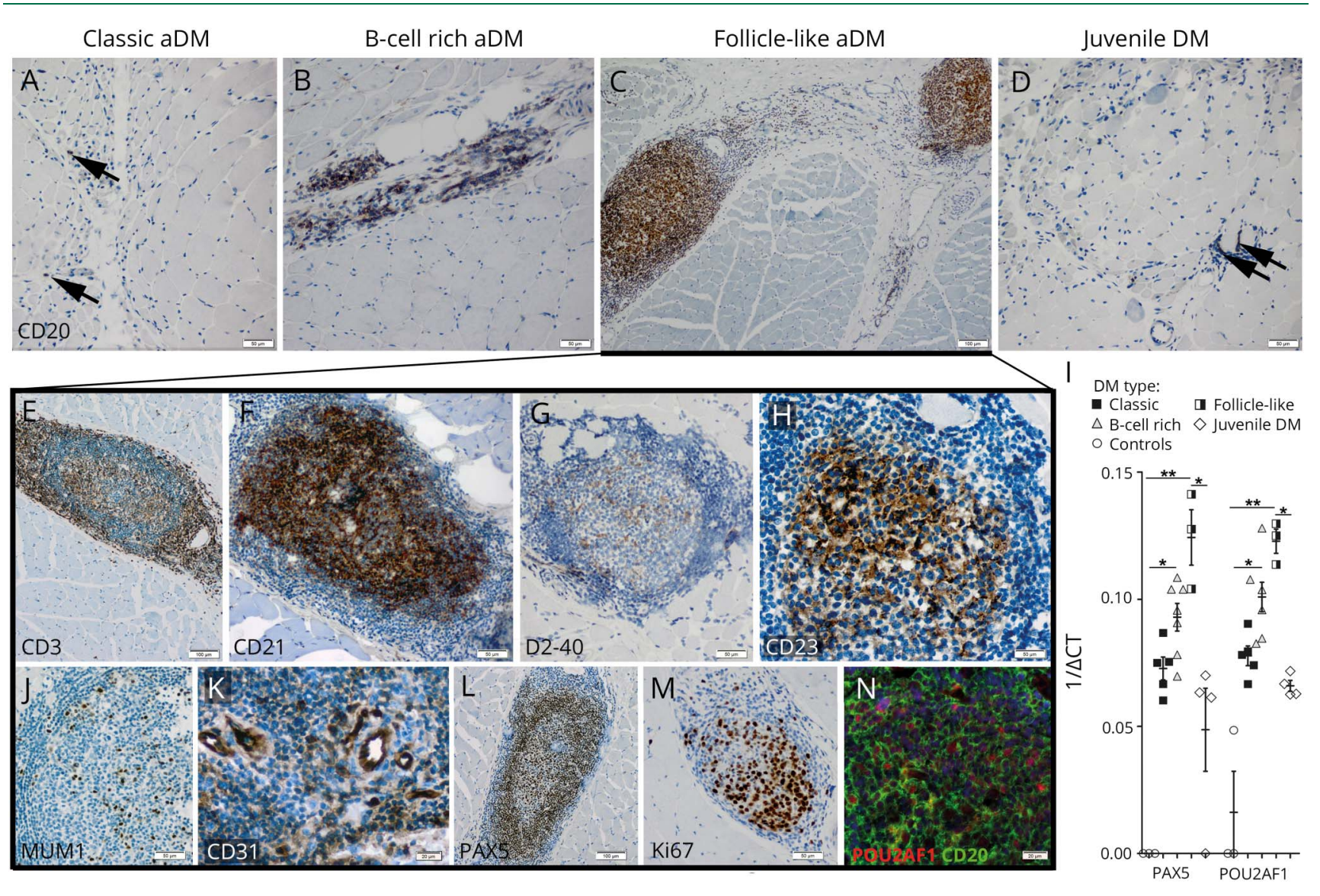

Muscle sections were stained with CD20 to highlight the B-cell content in different DM subgroups (A-D, arrowheads). ELSs showed clear compartmentalization of peripheral $C D 3^{+} T$ cells $(E)$ and $C D 21^{+}(F)$ B cells. The germinal center-like structures consisted of D2-40 ${ }^{+}$follicular dendritic cells $(F D C s)(G)$, $C D 23^{+} B$ cells $(\mathrm{H})$, MUM1 ${ }^{+} \mathrm{B}$ cells $(\mathrm{J})$, and CD $31^{+} \mathrm{HEVs}(\mathrm{K})$ with PAX5 ${ }^{+} \mathrm{B}$ cells mainly distributed around them (L). Increased proliferative activity in the B-cell-rich germinal center-like area was indicated by Ki67/MIB1 immunostaining (M). Immunofluorescent labeling demonstrated partial colocalization of central CD20 $\mathrm{B}$ cells with POU2AF1 (BOB-1) (N). (I) mRNA expression of PAX5 and POU2AF1 measured by real-time RT-PCR. The reciprocal $\triangle C T$ values are displayed to illustrate levels of gene expression of PAX 5 and POU2AF1, genes whose expression was not detectable in $\geq 2$ healthy controls. Results show mean \pm SEM. ${ }^{*} p<0.05$, $\star \star p<0.01$. DM = dermatomyositis; ELS = ectopic lymphoid structure; mRNA = messenger RNA; RT-PCR = real-time PCR.

2R), CXCR4 (figure 2S) CXCL12, CXCL13 (figure 4A), CCR7 (figure e-1C), IL7, and IL23A (figure e-1D) were significantly upregulated in B-cell-rich and follicle-like aDM compared with classic aDM and jDM, with highest expression of CCL19, CXCL12, CXCR4, and IL7 in follicle-like aDM.

\section{Th1- and Th17-mediated immunity is associated with B-cell aggregates in aDM}

Previous studies brought attention to the role of different $\mathrm{T}$ cell subsets in ectopic lymphoneogenesis and germinal center-like formation. Th1-mediated immunity in general is known to be specifically involved in the immunopathogenesis of DM. Of interest, cytokines linked to Th17 and Th1 immunity were significantly associated with B-cell aggregation and ELS formation in our study. In fact, Th17-associated cytokines IL7, IL12A, IL23A, and CCR6 ${ }^{22-24}$ were all significantly upregulated in B-cell-rich and follicle-like aDM (figure 1, C and D), with highest expression of IL7 and CCR6 in follicle-like $\mathrm{aDM}$. This was further supported by strong expression of Th1-specific CXCR3 ${ }^{25}$ (figure 2S), TNFA (figure e-1G, links.lww.com/NXI/A40), and INF $\gamma$ (data not shown) in follicle-like aDM, suggesting that ELS formation in DM muscle tissue is strongly influenced by Th1 and Th17 lineages.

\section{Morphologic and molecular analyses of B-cell infiltration, maturation, and ELS formation in DM}

To further characterize ectopic lymphoid follicle-like structures, we performed additional immunohistological stains and quantitative reverse-transcription PCR analysis of genes associated with lymphoid neogenesis and B-cell maturation. The center of the lymphoid follicle-like structures, mainly composed of $\mathrm{CD} 20^{+} \mathrm{B}$ cells (figure 3C), was surrounded by a $\mathrm{CD}^{+}{ }^{+}$T-cell-rich periphery (figure $3 \mathrm{E}$ ). High endothelial venules (HEVs; figure $3 \mathrm{~K}$ ) and $\mathrm{D} 2-40^{+}$follicular dendritic cells (figure $3 \mathrm{G}$ ) were only seen in follicle-like aDM, but not in samples of other subgroups (data not shown). Cytokines involved in lymphoid neogenesis such as CXCR5, CCL19, CCL21, CXCL12, CXCL13, LTA, LTB, and TNFSF13B were-with the exception of CXCR5 and LTA-highly expressed in all DM subgroups in comparison with healthy 
A

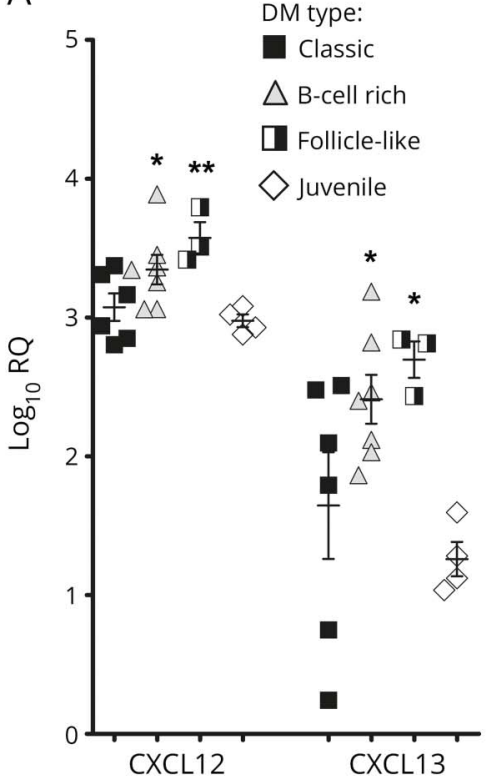

C
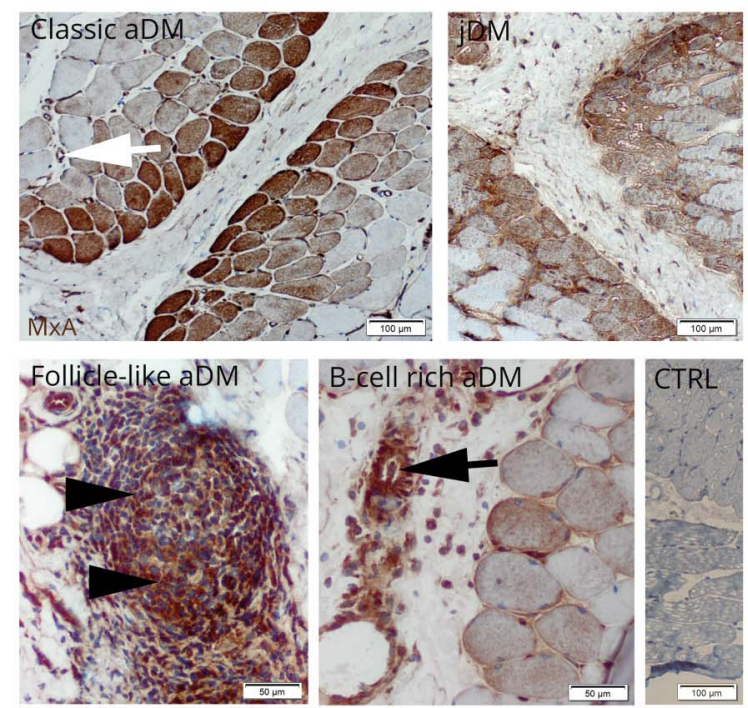

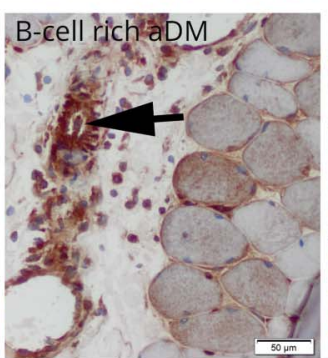

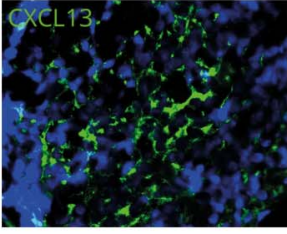
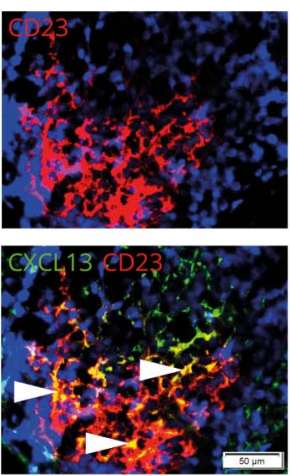

$\mathrm{D}$
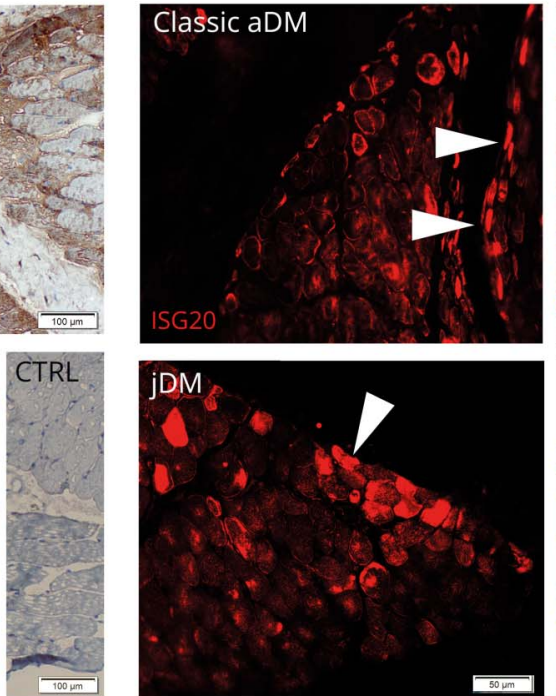

$\mathrm{CD}_{23}{ }^{+} \mathrm{B}$ cells are a source of CXCL13 as indicated by double immunofluorescent staining (A, arrowheads). Gene expression of CXCL12 and CXCL13 was illustrated by the log10 of fold change values compared with the normal controls. Results show mean $\pm \mathrm{SEM}$. ${ }^{\star} p<0.05,{ }^{*} p<0.01$. (B) EM revealed tubuloreticular inclusions (arrowheads) in the cytoplasm of a B-lymphocyte (solid and dashed boxes indicate magnified areas; * = mitochondrion). MxA staining revealed strong expression in the perifascicular area on myofibers and capillaries (C, arrows) in all cases and additional expression by B cells in Bcell-rich and follicle-like aDM (C, arrowheads). In contrast to healthy controls, muscle fibers of different DM subgroups showed upregulation of ISG20 (D; CRTL: normal control). aDM = adult dermatomyositis; DM = dermatomyositis; IFN = interferon; IM = intramuscular; ISG = interferon-stimulated gene; MxA = myxovirus resistance gene $A ; n=$ nucleus.

controls (figure 2, R and S; figures e-1F and G, links.lww.com/ NXI/A40). However, highest expression of these molecules was found in follicle-like aDM. Double immunofluorescence staining suggested that not only follicular dendritic cells but also $\mathrm{CD} 23^{+} \mathrm{B}$ cells seem to be a source of CXCL13 within these ectopic lymphoid follicle-like structures (figure 4A, arrowheads). We further investigated the differentiation state of infiltrating $\mathrm{B}$ cells and the mRNA and protein expression of POU2AF1 (BOB1), IRF4 (MUM1), PAX5, and PRDM1, genes/proteins involved in different functional or maturational B-cell subsets, e.g., within the germinal center. ${ }^{26-29}$ Specialized mature follicular $\mathrm{CD} 21^{+}$and $\mathrm{CD} 23^{+}$ germinal center $\mathrm{B}$ cells (figure 3, $\mathrm{F}$ and $\mathrm{H}$ ) were only detected within ELSs of follicle-like aDM, but not in other DM subgroups (data not shown). POU2AF1, IRF4, PAX5, and PRDM1 were highly upregulated in follicle-like aDM, slightly less expressed in B-cell-rich aDM, and showed significantly lower mRNA levels in classic aDM and jDM (figure 3I, figure e-1E). In follicle-like aDM, many POU2AF $1^{+}\left(\mathrm{BOB1}^{+}\right.$, figure $3 \mathrm{~N}$, figure $\mathrm{e}-1 \mathrm{H}$, arrowheads), $\mathrm{PAXS}^{+}$(figure $3 \mathrm{~L}$ ), and 
$\mathrm{MUM1}^{+}$(figure 3J) B cells were found in the center of the ELSs with few $\mathrm{CD} 138^{+}$plasma cells seen in the periphery (figure e-1I, arrowheads). Figure $3 \mathrm{~N}$ demonstrates the colocalization of POU2AF1 and CD20 in the follicle-like structures. POU2 $\mathrm{AF}^{+}$and $\mathrm{PAX}^{+}{ }^{+} \mathrm{B}$ cells were scarce in Bcell-rich aDM and absent in classic $\mathrm{aDM}$ or jDM (data not shown).

\section{Discussion}

Ectopic lymphoid neogenesis can occasionally be recognized in nonlymphoid tissues in different autoimmune and chronic inflammatory diseases such as rheumatoid arthritis, Sjögren syndrome, MS, Hashimoto thyroiditis, Helicobacter pylori-induced gastritis, and chronic hepatitis $\mathrm{C}$ virus infection. ${ }^{10,13,30}$ However, in DM, ELS formation with germinal center architecture seems to be an extremely rare phenomenon, which is very likely regulated by specific immune-inflammatory mechanisms. Therefore, our study further aimed at elucidating the impact of $B$ cells on the pathogenesis of DM using the follicle-like variant as a paradigm.

To characterize different histologic DM subgroups in terms of Bcell composition, skeletal muscle tissue of patients with DM was graded histologically and immunohistochemically for the presence and number of B cells, follicle-like aggregates, and the presence of ectopic germinal centers. We further evaluated the molecular signature of type 1 IFN-driven genes, known to be intimately involved in the pathogenesis of $\mathrm{DM}^{2,4,19,31}$ as well as genes implicated in lymphoangiogenesis. Consistent with the presence of dense B-cell aggregates, high expression of CXCL12, CXCL13, CCL19, LTA, LTB, CXCR4, CXCR5, CCR7, and IL23-genes known to induce lymphoneogenesis-was found at sites of chronic inflammation. These cytokines have all also been reported to be pivotal for B-cell migration. ${ }^{23,32,33}$ They were associated with increasing size of B-cell aggregates and formation of ELSs with compartimentalization of B- and T-cell zones, HEVs, and $\mathrm{D} 2-40^{+}$follicular dendritic cell networks. We further show that not only follicular dendritic cells but also $\mathrm{CD} 23^{+} \mathrm{B}$ cells as specialized mature B-cell subpopulations seem to be a source of CXCL13 expression within ELSs in aDM, suggesting a positive feedback mechanism that contributes to the recruitment of additional cells. ${ }^{34}$

Both TNFSF11 (RANKL) and TNFSF13B (BAFF) have been identified to play a role in several autoimmune diseases and are reported to be intimately involved in the development of ELSs in rheumatoid arthritis and Sjögren syndrome. ${ }^{35-37}$ Moreover, RANKL-deficient mice demonstrate profound defects in lymph node formation and B-cell development, which highlights its significance in lymph node organogenesis. ${ }^{38}$ Accordingly, we identified a significant increase of TNFSF11 and TNFSF13B expression in follicle-like aDM muscle samples, providing support that both are also associated with ELS formation in $\mathrm{aDM}$.

The formation of ectopic germinal centers with B-cell proliferation and different states of B-cell maturation is further

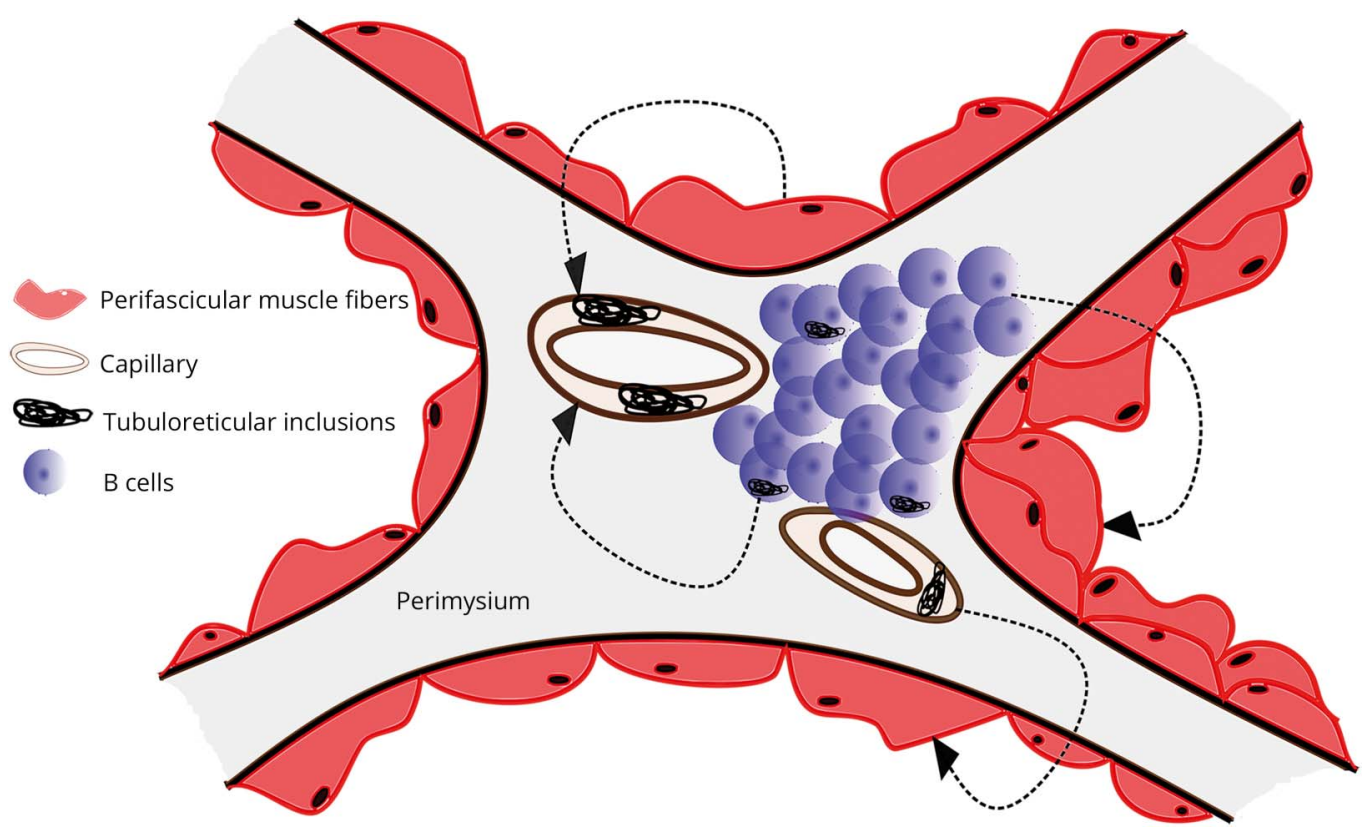

Skeletal muscle in DM shows perifascicular atrophy and loss of capillaries. Both myofibers and capillary endothelial cells express type 1 IFN-inducible gene transcripts. In addition, B cells within the endo- and perimysial space express type 1 IFN-inducible gene transcripts, e.g., MxA. Tubuloreticular inclusions within endothelial cells and B cells can be considered downstream markers of type 1 IFN signaling, illustrating specific damage of these structures. The reciprocal effects of IFNs on the perifascicular fibers, capillaries, and B cells may, once activated, feed an amplification loop that enhances adverse pathomechanisms in DM. DM = dermatomyositis; IFN = interferon; MxA = myxovirus resistance gene $\mathrm{A}$. 
highlighted by PAX5, IRF4 (MUM-1), and PRDM1 expressed by maturing B cells. These genes and proteins, involved in the terminal differentiation along plasma cells lineage, ${ }^{28,39}$ were highly expressed by proliferating B cells within the center of ELSs in follicle-like aDM.

Of note, we observed a significant upregulation of numerous genes implicated in different aspects of the IFN signature in Bcell-rich and follicle-like aDM muscle tissue in contrast to classic aDM and jDM. Although not selectively induced by type I IFN, previous studies provided evidence that most of these IFN-stimulated genes can be considered type I IFNdriven in the context of DM. ${ }^{4,40}$ In fact, we have investigated a large panel of genes representative for the type 1 IFN signature, e.g., MxA, ISG20, CCL19, CXCL12, CXCR4, and $\mathrm{IL} 7^{2,19,21}$ and others, reported to orchestrate T-cell responses, apoptosis, and adaptive immunity and found that they were all involved in DM, significantly correlating with the intrinsic amount of B cells. In fact, especially MxA staining revealed most striking staining results in B-cell-rich and follicle-like $\mathrm{aDM}$, illustrating that not only the ISGs are involved in numerous relevant pathomechanisms in DM but also highlights that therapies targeting type 1 IFNs may act effectively on multiple levels of the immune response.

In addition, we present that B-cell aggregates in aDM samples are associated with significant upregulation of cytokines involved in Th1- and Th17-mediated immunity, e.g., CXCR3, ${ }^{25}$ and TNFA.

We, therefore, hypothesize that the prominent in situ B-cell differentiation in skeletal muscle during DM may dysregulate (adaptive) immunity leading to excessive IFN response, which itself may fuel an amplification loop (figure 5) that enhances adverse pathomechanisms in DM. Our results suggest that these pathomechanisms seem to occur independent of the presence of ectopic germinal center formation, in both B-cell-rich and follicle-like aDM, which might, therefore, be considered to belong to the same clinicopathologic spectrum. Assessment of B-cell architecture, including ultrastructure and function, together with ISG analysis can be useful tools to stratify patients with $\mathrm{DM}$ and develop therapies targeting, e.g., B-cell immunity or type 1 IFN signaling for these disease subsets individually. Nevertheless, further prospective clinical studies will be needed to determine the effectiveness of such therapeutic options in the context of DM.

\section{Author affiliation}

From Charité-Universitätsmedizin Berlin (J.R., R.K., C.P., D.P., K.T., C.S., F.L.H., H.-H.G., W.S.); Corporate Member of Freie Universität Berlin (J.R., R.K., C.P., D.P., K.T., C.S., F.L.H., H.-H.G., W.S.); Humboldt-Universität zu Berlin (J.R., R.K., C.P., D.P., K.T., C.S., F.L.H., H.H.G., W.S.); Department of Neuropathology (J.R., R.K., C.P., D.P., K.T., C.S., F.L.H., H.-H.G., W.S.), Berlin Institute of Health; German Consortium for Translational Cancer Research (DKTK)
(J.R., R.K., F.L.H.), Partner site Charité Berlin; ZTB Zentrum für Transfusionsmedizin und Zelltherapie Berlin (K.T., C.S.), HLA Tissue Typing Laboratory; Department of Neuropathology (J.W.), Uniklinik RWTH Aachen; Department of Neuropathology (S.D.), Universitätsklinikum Freiburg; Berlin Institute of Health (BIH) (J.R., F.L.H.); Leibniz Science Campus Chronic Inflammation (F.L.H., W.S.), Berlin, Germany; Assistance Public-Hôpitaux de Paris (Y.A., O.B.), Université Pierre et Marie Curie, UMR974; Department of Internal Medicine and Clinical Immunology (Y.A., O.B.), and Department of Clinical Neurophysiology (T.M.), PitiéSalpêtrière University Hospital, France; and Department of (Neuro)Pathology (E.A.), and Department of Neurology and Neurophysiology (M.d.V.), Academic Medical Centre, University of Amsterdam, the Netherlands.

\section{Author contributions}

J. Radke, W. Stenzel, and H.H. Goebel: study concept and design, acquisition analysis, and interpretation of data. R. Koll, C. Preuße, D. Pehl, K. Todorova, C. Schönemann, Y. Allenbach, E. Aronica, M. de Visser, J. Weis, S. Doostkam, F.L. Heppner, T. Maisonobe, and O. Benveniste: acquisition, analysis, and interpretation of data.

\section{Acknowledgment}

The authors thank Hanna Plückhan, Cordula zum Bruch, and Petra Matylewski for excellent technical assistance and Yanick Crow for fruitful scientific discussion on IFN signaling in dermatomyositis. JR is a participant in the BIH-Charité Clinical Scientist Program funded by the Charité-Universitätsmedizin Berlin and the Berlin Institute of Health. This work was supported by the Leibniz ScienceCampus Chronic Inflammation (chronischeentzuendung.org).

\section{Study funding}

Deutsche Gesellschaft für Muskelkranke e.V. (DGM) to J.R.

\section{Disclosure}

J. Radke received research support from Deutsche Gesellschaft für Muskelkranke. R. Koll and C. Preuße report no disclosures. D. Pehl received research support from Deutsche Gesellschaft für Muskelkranke. K. Todorova, C. Schönemann, Y. Allenbach, and E. Aronica report no disclosures. M. de Visser is on the editorial board of Neuromuscular Disorders, Clinical Neurology, and Neurosurgery and is a member of the adjudication committee of Bristol-Myers Squibb. F.L. Heppner has a patent application for Modulators of Il-12 and/or IL23 for the prevention or treatment of Alzheimer's disease and is a founding scientist of Myosotis Therapeutics AG, which has licensing rights from the University of Zurich and the Charité-Universitätsmedizin Berlin on the Use of modulators of IL-12 and/or IL-23 for the prevention or treatment of Alzheimer's disease. J. Weis received travel funding and speaker honoraria from Ultragenyx; received royalties from Wiley-Blackwell; and received research support from the 
German Research Foundation, German Ministry of Science and Education, EU Joint Program Neurodegenerative Disease Research, JARA-BRAIN, Initiative Therapieforschung ALS e.v., and German Society for Muscle Diseases. S. Doostkam and T. Maisonobe report no disclosures. O. Benveniste served on the scientific advisory board of CSL Behring, Novartis, and LFB; received funding travel from CSL Behring and LFB; consulted for Novartis and CSL Behring; and received research support from LFB, Novartis, Shite, CSL Behring, DGOS/INSERM, PHRC, AFM, and The Myositis Association. H.H. Goebel served on the editorial board of Neuromuscular Disorders, Neuropathology and Applied Neurobiology, Brain Pathology, and Clinical Neuropathology. W. Stenzel served on the editorial board of Neuromuscular Disorders, Neuropathology, and Applied Neurobiology. Full disclosure form information provided by the authors is available with the full text of this article at Neurology.org/NN.

Received December 1, 2017. Accepted in final form February 2, 2018.

\section{References}

1. Hoeltzel MF, Oberle EJ, Robinson AB, Agarwal A, Rider LG. The presentation, assessment, pathogenesis, and treatment of calcinosis in juvenile dermatomyositis. Curr Rheumatol Rep 2014;16:467.

2. Preusse C, Allenbach Y, Hoffmann O, et al. Differential roles of hypoxia and innate immunity in juvenile and adult dermatomyositis. Acta Neuropathologica Commun 2016;4:45.

3. Miller FW, Cooper RG, Vencovsky J, et al. Genome-wide association study of dermatomyositis reveals genetic overlap with other autoimmune disorders. Arthritis Rheum 2013;65:3239-3247.

4. Greenberg SA, Pinkus JL, Pinkus GS, et al. Interferon-alpha/beta-mediated innate immune mechanisms in dermatomyositis. Ann Neurol 2005;57:664-678.

5. Gordon PA, Winer JB, Hoogendijk JE, Choy EH. Immunosuppressant and immunomodulatory treatment for dermatomyositis and polymyositis. Cochrane Database Syst Rev 2012;8:CD003643.

6. van de Vlekkert J, Hoogendijk JE, de Haan RJ, et al. Oral dexamethasone pulse therapy versus daily prednisolone in sub-acute onset myositis, a randomised clinical trial. Neuromuscul Disord 2010;20:382-389.

7. Rider LG, Yip AL, Horkayne-Szakaly I, et al. Novel assessment tools to evaluate clinical and laboratory responses in a subset of patients enrolled in the Rituximab in Myositis trial. Clin Exp Rheumatol 2014;32:689-696.

8. Salajegheh M, Pinkus JL, Amato AA, et al. Permissive environment for B-cell maturation in myositis muscle in the absence of B-cell follicles. Muscle Nerve 2010;42:576-583.

9. Radke J, Pehl D, Aronica E, et al. The lymphoid follicle variant of dermatomyositis. Neurol Neuroimmunol Neuroinflamm 2014;1:e19. doi: 10.1212/NXI.0000000000000019.

10. Jones GW, Bombardieri M, Greenhill CJ, et al. Interleukin-27 inhibits ectopic lymphoid-like structure development in early inflammatory arthritis. J Exp Med 2015; 212:1793-1802.

11. Noort AR, van Zoest KP, van Baarsen LG, et al. Tertiary lymphoid structures in rheumatoid arthritis: NF-kappaB-Inducing Kinase-positive endothelial cells as central players. Am J Pathol 2015;185:1935-1943.

12. Lopez De Padilla CM, Vallejo AN, Lacomis D, McNallan K, Reed AM. Extranodal lymphoid microstructures in inflamed muscle and disease severity of new-onset juvenile dermatomyositis. Arthritis Rheum 2009;60:1160-1172.

13. Aloisi F, Pujol-Borrell R. Lymphoid neogenesis in chronic inflammatory diseases. Nat Rev Immunol 2006;6:205-217.

14. Hoogendijk JE, Amato AA, Lecky BR, et al. 119th ENMC international workshop: trial design in adult idiopathic inflammatory myopathies, with the exception of inclusion body myositis, 10-12 October 2003, Naarden, The Netherlands. Neuromuscul Disord 2004;14:337-345.
15. Wedderburn LR, Varsani H, Li CK, et al. International consensus on a proposed score system for muscle biopsy evaluation in patients with juvenile dermatomyositis: a tool for potential use in clinical trials. Arthritis Rheum 2007;57:1192-1201.

16. De Visser M, Emslie-Smith AM, Engel AG. Early ultrastructural alterations in adult dermatomyositis: capillary abnormalities precede other structural changes in muscle. J Neurol Sci 1989;94:181-192.

17. Sallum AM, Varsani H, Holton JL, Marie SK, Wedderburn LR. Morphometric analyses of normal pediatric brachial biceps and quadriceps muscle tissue. Histology and Histopathol 2013;28:525-530.

18. De Paepe B. Interferons as components of the complex web of reactions sustaining inflammation in idiopathic inflammatory myopathies. Cytokine 2015;74: 81-87.

19. Rice GI, Melki I, Fremond ML, et al. Assessment of type I interferon signaling in pediatric inflammatory disease. J Clin Immunol 2017;37:123-132.

20. Greenberg SA. Dermatomyositis and type 1 interferons. Curr Rheumatol Rep 2010; 12:198-203.

21. Rusinova I, Forster S, Yu S, et al. Interferome v2.0: an updated database of annotated interferon-regulated genes. Nucleic Acids Res 2013;41:D1040-D1046.

22. Peters A, Pitcher LA, Sullivan JM, et al. Th17 cells induce ectopic lymphoid follicles in central nervous system tissue inflammation. Immunity 2011;35:986-996.

23. Luther SA, Bidgol A, Hargreaves DC, et al. Differing activities of homeostatic chemokines CCL19, CCL21, and CXCL12 in lymphocyte and dendritic cell recruitment and lymphoid neogenesis. J Immunol 2002;169:424-433.

24. Deteix C, Attuil-Audenis V, Duthey A, et al. Intragraft Th17 infiltrate promotes lymphoid neogenesis and hastens clinical chronic rejection. J Immunol 2010;184: 5344-5351.

25. Rabin RL, Alston MA, Sircus JC, et al. CXCR3 is induced early on the pathway of $\mathrm{CD} 4+\mathrm{T}$ cell differentiation and bridges central and peripheral functions. J Immunol 2003; 171:2812-2824.

26. Falini B, Fizzotti M, Pucciarini A, et al. A monoclonal antibody (MUM1p) detects expression of the MUM1/IRF4 protein in a subset of germinal center B cells, plasma cells, and activated T cells. Blood 2000;95:2084-2092.

27. Nutt SL, Tarlinton DM. Germinal center B and follicular helper T cells: siblings, cousins or just good friends? Nat Immunol 2011;12:472-477.

28. Cattoretti G, Shaknovich R, Smith PM, Jack HM, Murty VV, Alobeid B. Stages of germinal center transit are defined by $\mathrm{B}$ cell transcription factor coexpression and relative abundance. J Immunol 2006;177:6930-6939.

29. Gatto D, Brink R. The germinal center reaction. J Allergy Clin Immunol 2010;126 898-907.

30. Winter S, Loddenkemper C, Aebischer A, et al. The chemokine receptor CXCR5 is pivotal for ectopic mucosa-associated lymphoid tissue neogenesis in chronic helicobacter pylori-induced inflammation. J Mol Med 2010;88:1169-1180.

31. De Paepe B, Creus KK, De Bleecker JL. Role of cytokines and chemokines in idiopathic inflammatory myopathies. Curr Opin Rheumatol 2009;21:610-616.

32. Guedj K, Khallou-Laschet J, Clement M, et al. Inflammatory micro-environmental cues of human atherothrombotic arteries confer to vascular smooth muscle cells the capacity to trigger lymphoid neogenesis. PLoS One 2014;9:e116295.

33. Canete JD, Celis R, Yeremenko N, et al. Ectopic lymphoid neogenesis is strongly associated with activation of the IL-23 pathway in rheumatoid synovitis. Arthritis Res Ther 2015; 17:173.

34. Monin L, Khader SA. B cells produce CXCL13 in lymphoid neogenesis during chronic obstructive pulmonary disease. The new kid on the block? Am J Respir Crit Care Med 2013;187:1162-1164.

35. Mueller CG, Hess E. Emerging functions of RANKL in lymphoid tissues. Front Immunol 2012;3:261.

36. Pitzalis C, Jones GW, Bombardieri M, Jones SA. Ectopic lymphoid-like structures in infection, cancer and autoimmunity. Nat Rev Immunol 2014;14:447-462.

37. Yeo L, Toellner KM, Salmon M, et al. Cytokine mRNA profiling identifies B cells as a major source of RANKL in rheumatoid arthritis. Ann Rheum Dis 2011;70 2022-2028.

38. Kong YY, Yoshida H, Sarosi I, et al. OPGL is a key regulator of osteoclastogenesis, lymphocyte development and lymph-node organogenesis. Nature 1999;397: 315-323.

39. Cattoretti G, Angelin-Duclos C, Shaknovich R, Zhou H, Wang D, Alobeid B. PRDM1/Blimp-1 is expressed in human B-lymphocytes committed to the plasma cell lineage. J Pathol 2005;206:76-86.

40. Rodero MP, Decalf J, Bondet V, et al. Detection of interferon alpha protein reveals differential levels and cellular sources in disease. J Exp Med 2017;214: $1547-1555$. 


\title{
Neurology \\ Neuroimmunology \& Neuroinflammation
}

\author{
Architectural B-cell organization in skeletal muscle identifies subtypes of \\ dermatomyositis \\ Josefine Radke, Randi Koll, Corinna Preuße, et al. \\ Neurol Neuroimmunol Neuroinflamm 2018;5; \\ DOI 10.1212/NXI.0000000000000451
}

This information is current as of March 6, 2018

\section{Updated Information \& Services}

References

Subspecialty Collections

Permissions \& Licensing

\section{Reprints}

including high resolution figures, can be found at: http://nn.neurology.org/content/5/3/e451.full.html

This article cites 40 articles, 8 of which you can access for free at: http://nn.neurology.org/content/5/3/e451.full.html\#\#ref-list-1

This article, along with others on similar topics, appears in the following collection(s):

Autoimmune diseases

http://nn.neurology.org//cgi/collection/autoimmune_diseases Muscle disease

http://nn.neurology.org//cgi/collection/muscle_disease

Information about reproducing this article in parts (figures,tables) or in its entirety can be found online at:

http://nn.neurology.org/misc/about.xhtml\#permissions

Information about ordering reprints can be found online: http://nn.neurology.org/misc/addir.xhtml\#reprintsus

Neurol Neuroimmunol Neuroinflamm is an official journal of the American Academy of Neurology.

Published since April 2014, it is an open-access, online-only, continuous publication journal. Copyright

Copyright (C) 2018 The Author(s). Published by Wolters Kluwer Health, Inc. on behalf of the American

Academy of Neurology.. All rights reserved. Online ISSN: 2332-7812.

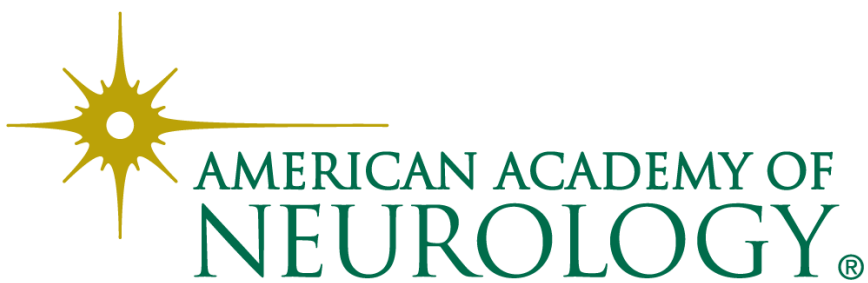

